\title{
Studying undisturbed autotrophic biofilms: still a technical challenge
}

\author{
C. Barranguet ${ }^{1, *}$, S. A. M. van Beusekom ${ }^{1}$, B. Veuger $^{1}$, T. R. Neu ${ }^{2}$, \\ E. M. M. Manders ${ }^{3}$, J. J. Sinke ${ }^{4}$, W. Admiraal ${ }^{1}$ \\ ${ }^{1}$ Department of Aquatic Ecology and Ecotoxicology, Institute for Biodiversity and Ecosystem Dynamics, Faculty of Science, \\ University of Amsterdam, Kruislaan 320, 1098 SM Amsterdam, The Netherlands \\ ${ }^{2}$ Department of Inland Water Research Magdeburg, UZF Centre for Environmental Research Leipzig-Halle, \\ Brückstrasse 3A, 39114 Magdeburg, Germany \\ ${ }^{3}$ Section Molecular Cytology, Swammerdam Institute for Life Sciences, Faculty of Science, University of Amsterdam, \\ Kruislaan 320, 1098 SM Amsterdam, The Netherlands \\ ${ }^{4}$ Netherlands Institute of Ecology, Centre for Coastal and Estuarine Ecology (NIOO-CEME), \\ PO Box 140, 4400 AC Yerseke, The Netherlands
}

\begin{abstract}
Biofilms in surface waters are characterized by their spatial structure and the heterogeneous distribution of the microorganisms that interact in a complex and dynamic way. Therefore, the assessment of phototrophic and heterotrophic biofilms' metabolic activity should be done without disturbing their structure. Several optical methods that allow the study of undisturbed living biofilms have been developed and are claimed to have high potential in the analysis of biofilms. However, natural biofilms can develop into thick packages of cells that may limit light penetration into the biofilm matrix, hindering the use of optical methods. In this paper we evaluate the use of nondestructive optical and destructive methods for the study of natural algal-bacterial biofilms. Pulse amplitude modulation (PAM) fluorimetry (with both single and multiple wavelength excitation) and confocal laser scanning microscopy (CLSM) are used as optical methods and compared to chemical extraction of plant pigments and exopolysaccharides. We demonstrate that the attenuation of the light intensity by the biofilm matrix represents a limitation to optical methods that is difficult to overcome in mature natural biofilms; but nevertheless, optical methods are very reliable for the study of thin or young biofilms. Apart from the biofilm thickness, the degree of compactness should also be taken into account. The density of some natural biofilms could be a limitation of CLSM especially if high molecular weight probes are used for specific biofilm components. In conclusion, a combination of both approaches still appears to be necessary in order to follow the complete developmental period of biofilms.
\end{abstract}

KEY WORDS: Biofilms · Microalgae · PAM fluorimetry · CLSM · Chlorophyll · Lectins · Bacteria Resale or republication not permitted without written consent of the publisher

\section{INTRODUCTION}

The consortia of microorganisms, algae and bacteria imbedded in a polysaccharide matrix and colonizing most substrates in surface waters are called biofilms. Autotrophic biofilms are currently the subject of a large number of studies focusing on the regulations of the organic carbon content in shallow environments (Battin et al. 1999), forming a crucial link at the base of the trophic web (Steinman 1996), purifying water (Percival et al. 2000) or, conversely, causing a nuisance by biofouling (Gawne et al. 1998).

A realistic assessment of the biofilm structure and distribution of organisms in the matrix is required for ecological and environmental studies (Wimpenny et al. 2000). This goes beyond the simple identification of the microbial groups present, as the microbial activity is influenced by the biofilm spatial structure (Okkerse et 
al. 2000), which is far from homogeneous. Biofilms are formed by heterogeneous clusters of cells and voids connected by channels (Herbert-Guillou et al. 2000).

Methods that disrupt the biofilm structure have been most frequently used when attempting an assessment of biofilm algal biomass as chlorophyll a (chl a), photosynthesis (Goto et al. 2001) and extracellular polymeric substances (EPS) production (Becker 1996). Lately, techniques that do not disrupt biofilm structure and its microgradients have been given priority (de Beer et al. 1994, Neu \& Lawrence 1997). Optical methods have arisen as new promising techniques in biofilm studies, and among them confocal laser scanning microscopy (CLSM) has been preferred to other types of microscopy, because it allows the study of live, fully hydrated biofilms (Neu \& Lawrence 2002). CLSM provides simultaneous information about the 3-dimensional (3D) structure of the biofilms and the identification of the different components, either by autofluorescence (algae) or by using specific fluorescent dyes for bacterial DNA or EPS glycoconjugates (Neu et al. 2001, Staudt et al. 2003). In algal biofilms, pulse amplitude modulation (PAM) fluorimetry allows the measurement of algal photosynthetic activity, maximum quantum yield and algal biomass on undisturbed biofilm samples (Barranguet \& Kromkamp 2000).

An accurate assessment of biofilm structure and activity by optical methods relies on the penetration of light through the whole thickness of the biofilm. Autotrophic biofilms can develop into thick (mm deep) compact layers of cells, creating a barrier that will attenuate the optical signal and/or limit the penetration of (fluorescent) dyes. In consequence, problems may arise in the resolution and sensitivity of methods that rely on the use of light. This paper focuses on the comparative study of natural autotrophic biofilms by destructive and non-destructive techniques. The light attenuation by the biofilm is measured and compared with the signal attenuation when using PAM fluorimetry and CLSM. The results of algal biomass and EPS production determined by destructive chemical and non-destructive optical methods on mixed autotrophic biofilms of different ages are compared. The advantages and limitations of both types of technologies are discussed, with the aim of clarifying when which method should be preferred.

\section{MATERIALS AND METHODS}

Biofilms ( $3 \mathrm{~d}$ to $10 \mathrm{wk}$ old) were collected at the infiltration dunes of Leiduinen $\left(52^{\circ} 20^{\prime} 44^{\prime \prime} \mathrm{N}, 4^{\circ} 34^{\prime} 38^{\prime \prime} \mathrm{E}\right.$; NW Netherlands) in summer 2001. After pre-treatment water from the river Rhine is transported to the dunes, where infiltration takes place by gravity. Our sampling sites were located at one of the lower storage canals and at the central basin, where all infiltrated water is collected. Floating polyethylene racks, approximately $25 \mathrm{~cm}$ below the water surface (total depth $1.5 \mathrm{~m}$ ), held the glass discs used as artificial substratum. The discs' area was $1.5 \mathrm{~cm}^{2}$, with a $1 \mathrm{~mm}$ thickness for all measurements except CLSM, for which cover glasses $(0.17 \mathrm{~mm})$ were used, enabling microscopic observation. The biofilms were directly transported to the laboratory in cool-boxes filled with water from the location. Biofilm samples were processed immediately at the laboratory for CLSM analysis, in vivo fluorescence measurements (PAM fluorimetry) and carbohydrate extraction as described below.

Optical methods. Light attenuation: The light attenuation of a biofilm was calculated as the difference between the incident irradiance and the irradiance after the passage through the biofilm; it is expressed as a percentage of the incident irradiance. It was measured by placing a glass disc colonized with biofilm on the $2 \pi$ sensor of a light meter (Li-Cor LI 1400). The value was corrected for the light attenuation of a clean glass disc. These measurements were done with biofilms from different locations studied in Leiduinen, for the whole period of biofilm development. To correlate light attenuation with algal biomass, the chl a concentration of each of the biofilms tested was also measured using the same discs.

In vivo fluorescence: Two different PAM fluorimeters were used during this study: a Water-PAM/F and a PHYTOPAM (Heinz Walz GmbH). The former excites the reaction centers at $650 \mathrm{~nm}$. The PHYTOPAM cannot be used under actinic light conditions, but it can be used to measure at 4 different excitation wavelengths simultaneously. The LEDs generate pulsed light at a wavelength of 470 (blue), 525 (green), 590 (orange) and $650 \mathrm{~nm}$ (red). Because each cyanobacterial class or each algal class contains a specific combination of photosynthetic pigments, each group will have a specific excitation spectrum; such groupspecific excitation spectra can be recorded from single species cultures and used to quantify the abundance of the different algal classes in a mixed biofilm by deconvolution of the overall fluorescence signal. The test species used in this study were: Selenastrum capricornutum Printz for the green algae; Leptolyngbia foveolarum (Raberhorst ex. Gomont) for the cyanobacteria; and 3 different spectra of different benthic diatom species were tested -Achnanthes lanceolata (Brébisson), Navicula trivialis Lange-Bertalot and Fragilaria capucina Desmazières.

In vivo fluorescence measurements were conducted 2 to $3 \mathrm{~h}$ after collection of the samples from the field. For each location, 2 random points were measured per disc on a total of 4 discs. Prior to the measurements, the 
samples were incubated in the dark for $20 \mathrm{~min}$. Also in the dark, the measurements were performed keeping the biofilm immersed in field water, with their surface at a constant distance of $4 \mathrm{~mm}$ from the measuring cone.

The minimal fluorescence signal of dark-adapted cells $\left(F_{0}\right)$, which can be used as an indirect indicator of biomass, was measured on the Water-PAM/F and PHYTOPAM fluorimeters. A background noise correction was made for all measurements, by measuring the signal from a clean submerged disc. Further information describing the PAM technique and its principles is available in Genty et al. (1989); see Barranguet \& Kromkamp (2000) for its use on benthic microalgae.

Confocal laser scanning microscopy (CLSM): CLSM analysis was used as a non-destructive method to monitor the development of the auto- and heterotrophic biofilm compartments simultaneously. A 3D image of a biofilm is obtained by combining a series of optical sections taken at different depths in the biofilm, by means of image analyses. In addition, the relative contribution of algae, bacteria and EPS can be quantified as a function of depth in the biofilm ( $z$-profile).

Microalgal biomass was quantified via chlorophyll auto-fluorescence (absorption maximum at $668 \mathrm{~nm}$ ). Bacterial DNA was stained with Syto 9 (Molecular Probes). EPS was stained using a fluorescently labeled lectin of Canavalia ensiformis (Con-A, tetramethylrhodamine conjugated; Molecular Probe). The intensity of Con-A fluorescence was used to quantify EPS. Con-A appeared to be a more general dye for EPS than any of the other lectins tried, i.e. Helix aspersa, Phaseolus vulgaris, Triticum vulgaris and Ulex europaeus (all tetramethylrhodamine conjugated; Sigma-Aldrich). A detailed description of the use of fluorescent dyes and autofluorescence in biofilms can be found elsewhere (Lawrence et al. 1998, Neu \& Lawrence 1997).

For each type of biofilm, 3 replicate samples were examined. The biofilms grown on the discs were placed in a PVC holder containing individual wells for each glass and stained as follows. The excess water was removed with filtration paper, and 7 drops of a $0.1 \mathrm{~g} \mathrm{l}^{-1}$ Con-A solution were added to each disc, incubated for $30 \mathrm{~min}$ at $20^{\circ} \mathrm{C}$ and subsequently carefully rinsed 4 times with filtered sterile bi-distilled water. Next, 7 drops of a $0.835 \mu \mathrm{M}$ Syto- 9 solution were applied to every disc. The biofilms were incubated for $5 \mathrm{~min}$ at $20^{\circ} \mathrm{C}$. After the staining was completed the discs were rinsed and examined using a Zeiss model LSM 510 (inverted) laser scanning microscope equipped with 2 helium-neon lasers (543 and $633 \mathrm{~nm}$ ) and an argon-ion laser (488 nm) (Muller 2002).

All observations were performed using a 20×/0.75 NA, working distance $0.61 \mathrm{~mm}$ objective (Zeiss, PlanApochromat ${ }^{\circledR}$ ). The $0.17 \mathrm{~mm}$ thick glass disc was fixed in a custom-made device that allowed observation of the fully hydrated biofilm through the glass discs without disturbance. A series of optical sections were recorded at $5 \mu \mathrm{m}$ intervals, starting at the glass disc surface, resulting in a 3D image of the biofilm. The maximum observable depth in the biofilms was $300 \mu \mathrm{m}$. In order to reduce optical cross-talk between the signals from algae, bacteria and EPS, the images were recorded in line sequential scanning mode (multi-tracking). The algae were excited at $633 \mathrm{~nm}$, and the emitted signal was filtered using a long-pass $650 \mathrm{~nm}$ filter. Con-A was excited at $543 \mathrm{~nm}$, and the emitted signal was detected using a 560-615 nm bandpass filter. Syto- 9 was excited at $488 \mathrm{~nm}$ and detected using a 505-550 nm band-pass filter. This resulted in clear separation of the 3 groups into 3 cross-talk free channels.

For image analysis, four 3D images per glass disc were recorded, producing twelve 3D images per location per test day. For each 3D image the total contribution of algae, EPS and bacteria as a function of depth was calculated by summing the individual channels per optical section, resulting in a $z$-profile (software by Mark Savenije). The data were corrected for background signal. The mean contribution of algae, EPS and bacteria per disc was determined by averaging the $4 z$-profiles. Biofilm thickness per disc was determined as the distance between the beginning of the biofilm and the point in the biofilm where the maximum value of the 3 signals became less than $20 \%$ of the maximum value reached by one of the signals. The average biofilm thickness and the relative contribution of algae, EPS and bacteria per sample day per location were finally calculated by averaging the results of the 3 individual glass discs.

Extraction methods. The biofilm samples used for pigment determination were frozen $\left(-80^{\circ} \mathrm{C}\right)$ until the HPLC (high-performance liquid chromatography) analyses could be performed. Pigments were extracted from freeze-dried biofilm samples with $95 \%$ methanol and $4 \%$ ammonium acetate, sonicated for $1 \mathrm{~h}$ in an ice bath and analyzed by HPLC according to the method described in Barranguet et al. (1997).

The carbohydrate fraction of the EPS was measured spectrophotometrically (Shimadzu UV-1601) using the phenol-sulphuric acid method (Dubois 1959): $200 \mu \mathrm{l}$ phenol ( $5 \% \mathrm{v} / \mathrm{v})$ is added to $200 \mu \mathrm{l}$ sample, followed by $1 \mathrm{ml} \mathrm{H}_{2} \mathrm{SO}_{4}(18 \mathrm{M})$. The carbohydrate concentration in the samples was determined by comparing the measured absorption values with those of a calibration range of fresh glucose standards of known concentrations between 10 and $200 \mu \mathrm{g} \mathrm{ml}^{-1}$.

For the EPS extraction, a new protocol had to be adapted for freshwater biofilms, because the water extraction currently used for field samples of micro- 
benthic algae (Staats 1999) proved to be insufficient for a complete extraction of the carbohydrates in our biofilms. Two extraction steps were used in order to be able to distinguish 2 different fractions of extracellular carbohydrates. The first step in bi-distilled water enabled the extraction of the loose (soluble) EPS fraction (Nielsen \& Jahn 1999), and a second eluent, strong enough to extract the capsular or bound fraction of EPS, was selected using natural biofilms from the studied location.

A set of different eluents $\left(\mathrm{NaOH}, \mathrm{NaCl}, \mathrm{Na}_{2}\right.$ EDTA and $\mathrm{H}_{2} \mathrm{SO}_{4}$ ) was tried out at different concentrations using a range of temperatures and extraction times. After centrifugation, the pellet was stained with Alcian Blue $(0.1 \%$ [w/v] Alcian Blue in $0.5 \mathrm{M}$ acetic acid; Rince et al. 1999, Staats 1999) to check the extraction efficiency of each eluent. Microscopic observation of the stained sample allowed us to determine the intactness of the cells and whether any extracellular (loose and/or capsular) carbohydrates had remained after the extraction.

Sulphuric acid showed the highest extraction efficiency at molarities between 0.1 and $0.2 \mathrm{M}$, with the best balance between extraction efficiency and cell lysis, while molarities over ca. $4 \mathrm{M}$ tended to cause cell lysis. The extraction efficiency increased with increasing temperature up to $95^{\circ} \mathrm{C}$ without causing any cell damage. The duration of the extraction time was checked up to $2 \mathrm{~h}$, and $30 \mathrm{~min}$ was selected. Before proceeding with the extraction, however, the biofilms were scraped from the discs and blended using a highspeed (20000 rpm) mini blender (Ultra-Turrax, TP 18-10, Janke \& Kunkel) to allow good contact with the eluent. Destruction techniques such as shredding the film with a razorblade, sonication, shaking and mixing, used successfully on other types of biofilms (Nielsen \& Jahn 1999, Smith \& Underwood 2000), did not consistently improve the extraction efficiency, as the biofilms used in this study appeared to be relatively compact.

As a result of these pilot experiments, the following extraction protocol was used. Biofilms were scraped from the glass discs using a razorblade and suspended in bi-distilled water ( 1 to 5 discs in 3 to $5 \mathrm{ml}$, depending on the biofilm thickness) in a test tube. The suspension was blended for ca. $5 \mathrm{~s}$ to destroy large biofilm lumps and then centrifuged for $5 \mathrm{~min}$ at $3500 \mathrm{rpm}$. A $2 \mathrm{ml} \mathrm{sub-}$ sample of the liquid was kept in an Eppendorf vial for phenol-sulphuric acid assay. This fraction is considered as representative of the amount of 'loose' extracellular carbohydrates in the biofilm. The pellet was resuspended in $0.1 \mathrm{M} \mathrm{H}_{2} \mathrm{SO}_{4}$ (3 to $5 \mathrm{ml}$ ) and blended for 1 to $2 \mathrm{~s}$ and subsequently incubated at $95^{\circ} \mathrm{C}$ in a water bath for $30 \mathrm{~min}$ (shaking every 5 to $10 \mathrm{~min}$ ). After the incubation, the sample was centrifuged for $5 \mathrm{~min}$ (3500 rpm). From the supernatant, a $2 \mathrm{ml}$ subsample was kept in an Eppendorf vial for phenol-sulphuric acid assay. This was considered as representative for the amount of 'bound/capsular' extracellular carbohydrates in the biofilm. The remaining pellet was resuspended in bi-distilled water ( 3 to $5 \mathrm{ml}$ ) and blended for 1 to $2 \mathrm{~s}$; a $2 \mathrm{ml}$ subsample was kept for phenolsulphuric acid assay. This fraction represents the concentration of intracellular carbohydrates. All extracted samples were stored in Eppendorf vials at $-20^{\circ} \mathrm{C}$ in the dark until quantification.

The extraction protocol as described above appeared to be unsuitable for very thin films ( 3 and $6 \mathrm{~d}$ old) due to the lack of sufficient biomass. For these films the extraction protocol was adjusted as follows. For each sample, biofilms from 40 glass discs were pooled and directly incubated in $20 \mathrm{ml} 0.1 \mathrm{M} \mathrm{H}_{2} \mathrm{SO}_{4}$ at $95^{\circ} \mathrm{C}$ for $30 \mathrm{~min}$ and shaken regularly. The suspension was pipetted into test tubes and centrifuged $(5 \mathrm{~min}$ at $3500 \mathrm{rpm})$. The extracted carbohydrates in the supernatant were pre-concentrated for the phenol-sulphuric acid measurement by precipitation in cold ethanol $\left(96 \%\right.$ at $-20^{\circ} \mathrm{C}$ for at least $12 \mathrm{~h}$; sample:EtOH $\left.=1: 4\right)$. Precipitated samples were centrifuged (5 min at $3500 \mathrm{rpm}$ ), after which the ethanol was discarded and the pellet was resuspended in a small volume of bidistilled water for the phenol-sulphuric acid assay.

\section{RESULTS}

Light attenuation by the biofilms followed the increase in chl a exponentially, and close to $90 \%$ of the incident light was absorbed by the biofilms with chl a contents around $5 \mu \mathrm{g} \mathrm{cm} \mathrm{cm}^{-2}$ (Fig. 1). The physiognomy of the biofilm did not play a role in the proportion of light absorbed by the biomass; more incrusting biofilms did not attenuate more incident light than less cohesive biofilms. There was no indication of other pigmented particles, such as detritus, that could affect the light attenuation. Consistent with the observed light attenuation, the fluorescence signal measured by the Water-PAM fluorimeter was also attenuated by the biofilms. Despite the exponential light attenuation, $F_{0}$ predicted accurately chl a concentrations for biofilms

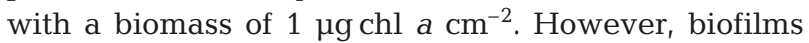

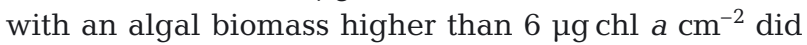
not show a parallel increase in $F_{0}$ values (Fig. 2a).

The PHYTOPAM was at least as sensitive as the Water-PAM, detecting chl a values of $0.4 \mu \mathrm{g} \mathrm{chl} \mathrm{a} \mathrm{cm}^{-2}$ in the biofilms, and it showed a saturation of the signal similar to the one observed by the Water-PAM (chl a $>7 \mu \mathrm{g} \mathrm{chl} \mathrm{a} \mathrm{cm}^{-2}$; data not shown). PHYTOPAM also gave an estimation of the relative contribution of the 3 major algal groups to the biofilm algal biomass; however, when choosing different diatom species as a 


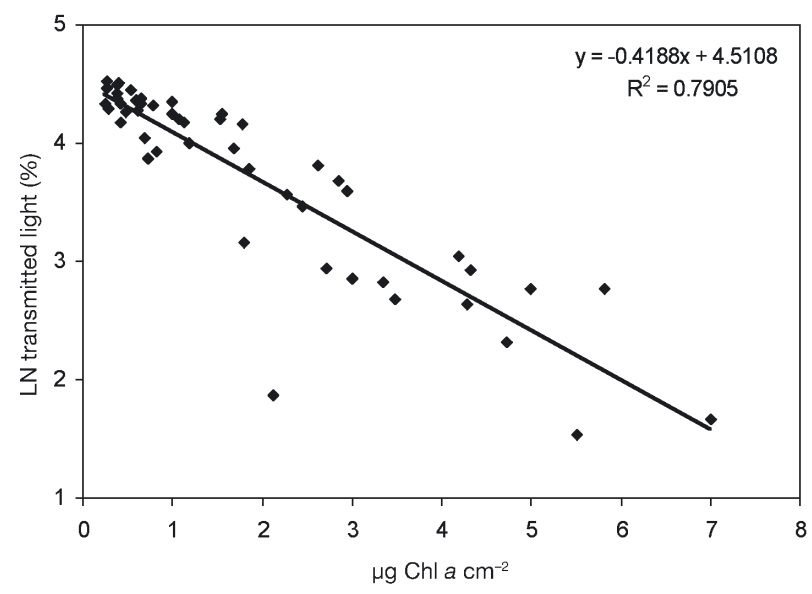

Fig. 1. Percentage values of transmitted light reaching the base of the biofilms plotted against their respective chl a concentration. Incident light: $1700 \mu \mathrm{mol} \mathrm{m}{ }^{-2} \mathrm{~s}^{-1}$
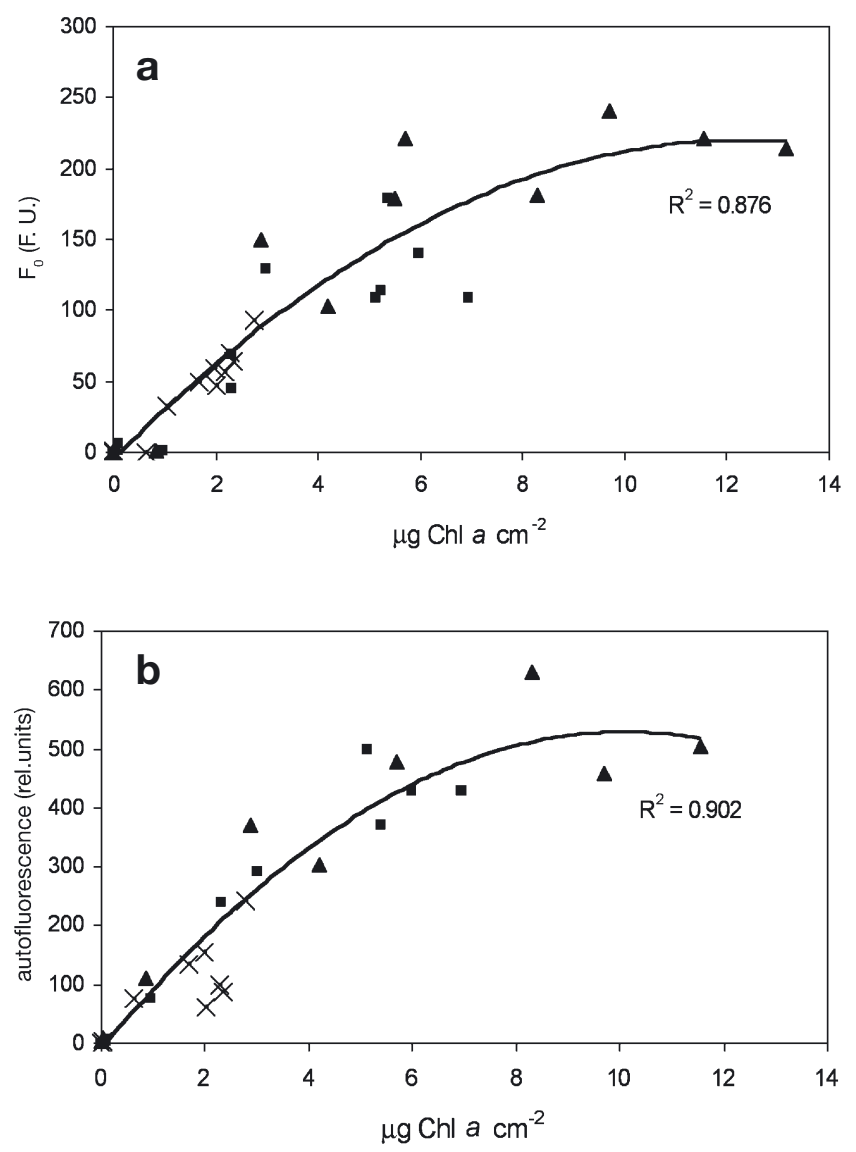

Fig. 2. Chlorophyll fluorescence plotted against chl a measured by HPLC (sum of chl a + allomers and isomers) for natural algal biofilms growing on glass discs. Different symbols correspond to biofilms grown at different locations. Trend lines are given for guidance only. (a) Fluorescence measurement of dark-adapted minimum fluorescence $\left(F_{0}\right)$ with a PAM fluorimeter. (b) CLSM data of chlorophyll autofluorescence. $\mathrm{X}$ : very compact grazed biofilms reference, different results of the relative contribution of diatoms to the total fluorescence were obtained for the same data set; hence the representation of the 3 groups may give false figures (Table 1). Light microscopy observations revealed that the biofilms were composed mainly of a mixture of the 3 groups, dominated by diatoms, either those attached by a short stalk (Achnanthes minutissima, Gomphonema spp.) or those that are motile (such as species of Navicula), followed by green colonial algae (such as Coleochaete orbicularis or Chaetophora sp.), and some filamentous cyanobacteria (Heteroleibleinia kutzingii).

Measurements of algal autofluorescence by CLSM allowed us to visualize biofilms down to a depth of $200 \mu \mathrm{m}$ and more; however, in the deeper layers, there was attenuation of the fluorescence signal, chl a concentrations being underestimated with respect to the HPLC measurements in mature biofilms (Fig. 2b). In the case of CLSM autofluorescence, biofilms with different physiognomies showed a different relation between chl $a$ and autofluorescence, indicating that compactness may diminish the signal detection by CLSM. Alternatively, CLSM was able to detect algal biomass on very young biofilms, below the HPLC detection limit, as indicated in Fig $2 b$.

When examining the vertical profiles of the 3 different CLSM parameters measured (algal autofluorescence, bacterial stain and EPS stain) on biofilms in different developmental stages, the attenuation and underestimation of the 3 parameters became clear. Fig. 3 shows 3 examples of CLSM measurements in young (6 d old; Fig. 3a) and mature (49 d old; Fig. 3b,c) biofilms. In the young biofilm, the vertical distribution of EPS and microorganisms is accurately represented, with a maximum at the base of the biofilm. For the mature, and hence thicker biofilm, Fig. 3b shows how the signal becomes attenuated with depth; the biofilms

Table 1. Contribution of each algal group (\%) to the total fluorescence signal measured with the PHYTOPAM, using 4 different sets of references on the same biofilm sample. (1) Achnanthes lanceolata was used as a reference for diatoms, Selenastrum capricornutum for the chlorophytes and Leptolyngbia foveolarum for the cyanobacteria. (2) Navicula trivialis was used as a reference for diatoms, $S$. capricornutum for the chlorophytes and $L$. foveolarum for the cyanobacteria. (3) Fragilaria capucina was used as a reference for diatoms, $S$. capricornutum for the chlorophytes and $L$. foveolarum for the cyanobacteria. (4) Standard reference spectra included in the PHYTOPAM software

\begin{tabular}{|lcccc|}
\hline & $(1)$ & $(2)$ & $(3)$ & $(4)$ \\
\hline Cyanobacteria & 25 & 0 & 1 & 14 \\
Chlorophytes & 0 & 23 & 21 & 28 \\
Diatoms & 75 & 76 & 78 & 57 \\
\hline
\end{tabular}




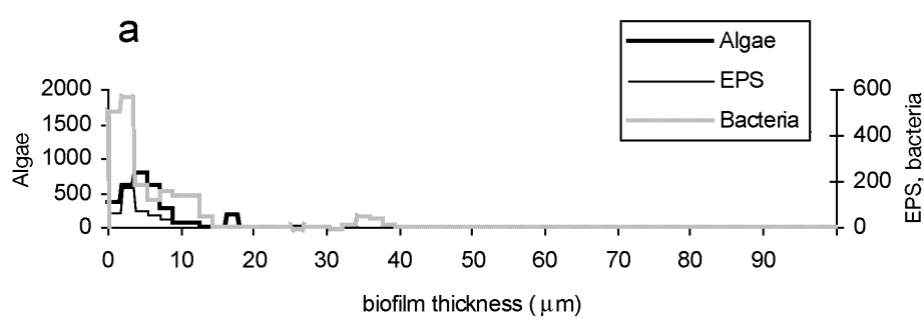

b

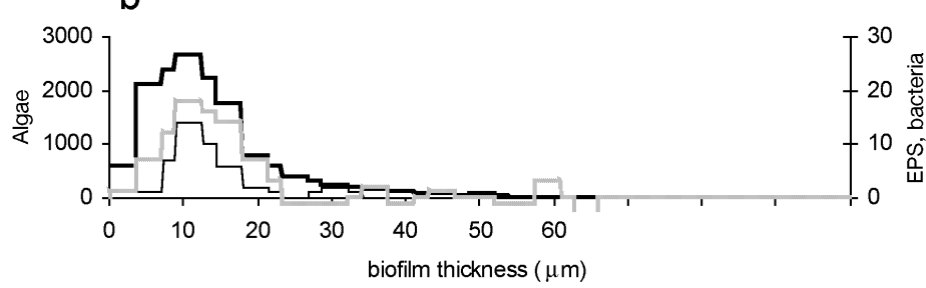

C

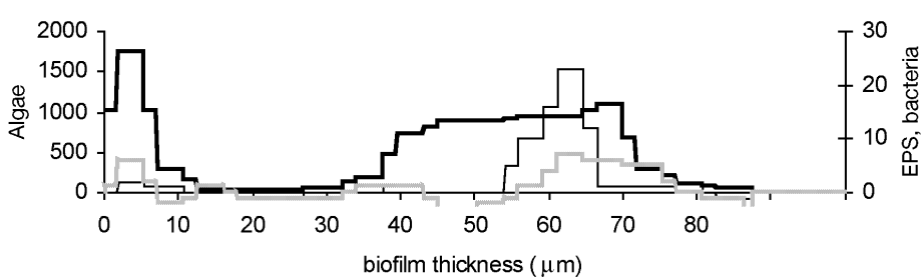

Fig. 3. CLSM signal measured on natural biofilms of different age. The signals represented (in relative units) correspond to the different biofilm components: algae (autofluorescence), bacteria (DNA stained with Syto 9) and EPS (stained with Con-A). (a) $6 \mathrm{~d}$ old biofilm; (b,c) 49 d old biofilms: compact and with a floating layer, respectively

were thicker than $35 \mu \mathrm{m}$, and the sum of the signal is strongly attenuated beyond that depth. A particular case is that of mature, almost senescent biofilms (Fig. 3c), where the upper part of the biofilm is getting loose, producing a 2-layer biofilm with a void between the 2 layers. This empty space allows for better penetration of the laser light within the biofilm matrix and better detection of the induced fluorescence signals. However, the thick biofilm layer obstructed the penetration of the dyes used (from above) and the CLSM (from below) therefore underestimated or even invalidated the contribution of EPS and bacteria to the biofilm biomass. Theoretically, this effect could be less strong when excitation light, emission light and stain all come from above.

This underestimation also has consequences when attempting to measure biofilm thickness and for 3D reconstructions using CLSM data. Fig. 4 shows the temporal evolution of biofilms thickness and how the presence of voids caused an abrupt increase in the detected signal at the end of the colonization period for the thicker biofilms (biomass above $8 \mu \mathrm{g} \mathrm{chl} \mathrm{a} \mathrm{cm}^{-2}$ ). We concluded that, although individual biofilm com- ponents could be visualized up to $200 \mu \mathrm{m}$ depth, for our data set and the present set-up, the assessment of biofilm thickness by summing of the signal in order to quantify its components was not possible for $>35 \mu \mathrm{m}$ thick biofilms.

The quantification of EPS in the biofilms did not show good agreement with the EPS extraction, neither in the soluble fraction, in the bound fraction nor in a sum of both (Fig. 5). Although CLSM proved to be more sensitive than the chemical extraction of EPS in the young biofilms $(<1 \mathrm{wk}$ old $)$, there was an underestimation for biofilms older than 1 mo. When the EPS concentration measured by CLSM showed a plateau, the chemical extraction indicated a steady increase until Day 50. The large standard deviations of CLSM (not shown for the EPS chemically extracted) may be due to the already-cited differences in light penetration, signal attenuation and limited or uneven penetration of the dye in heterogeneous biofilms. The underestimation of EPS by CLSM is larger in compact, heavily grazed biofilms (Fig. 5a) than in biofilms that have a larger biomass but are less compact (Fig. 5b).

The other parameter measured by CLSM, bacterial biomass, showed a stabilization of the bacterial numbers after Day 12, and a decrease for some mature biofilms after Day 40 (example in Fig. 3), which is highly improbable. However, the early stages of biofilm development were accurately assessed by CLSM, which provided a good 3D reconstruction of the biofilm structure, together with the relative contribution of the different biofilm components, microalgae, EPS, and bacteria. The abundance of such components changes rapidly in time, from an EPS dominance in the early stages (conditioning film) to an increase in algal and bacterial biomass later on (Fig. 6).

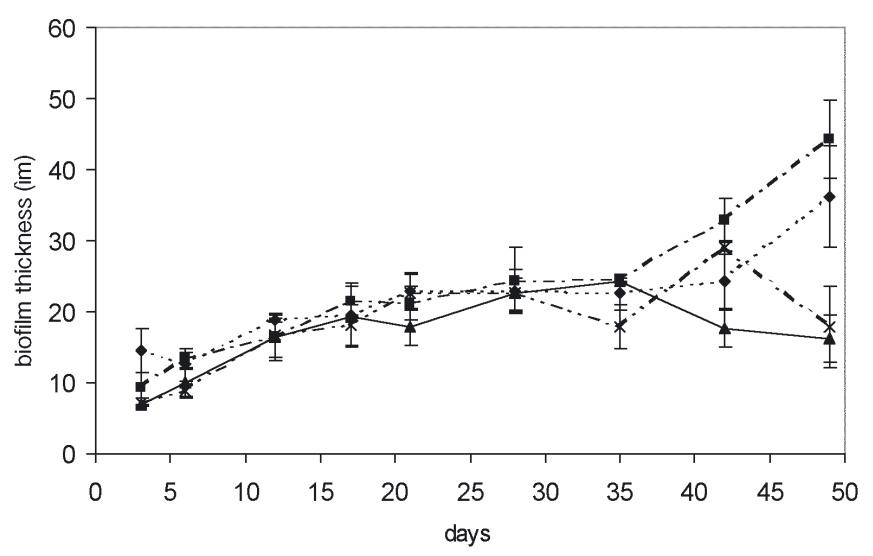

Fig. 4. Biofilm thickness as measured by CLSM for grazed and non-grazed autotrophic biofilms growing at Leiduinen. Note that after Day 12 the biofilm thickness seems to stabilize 

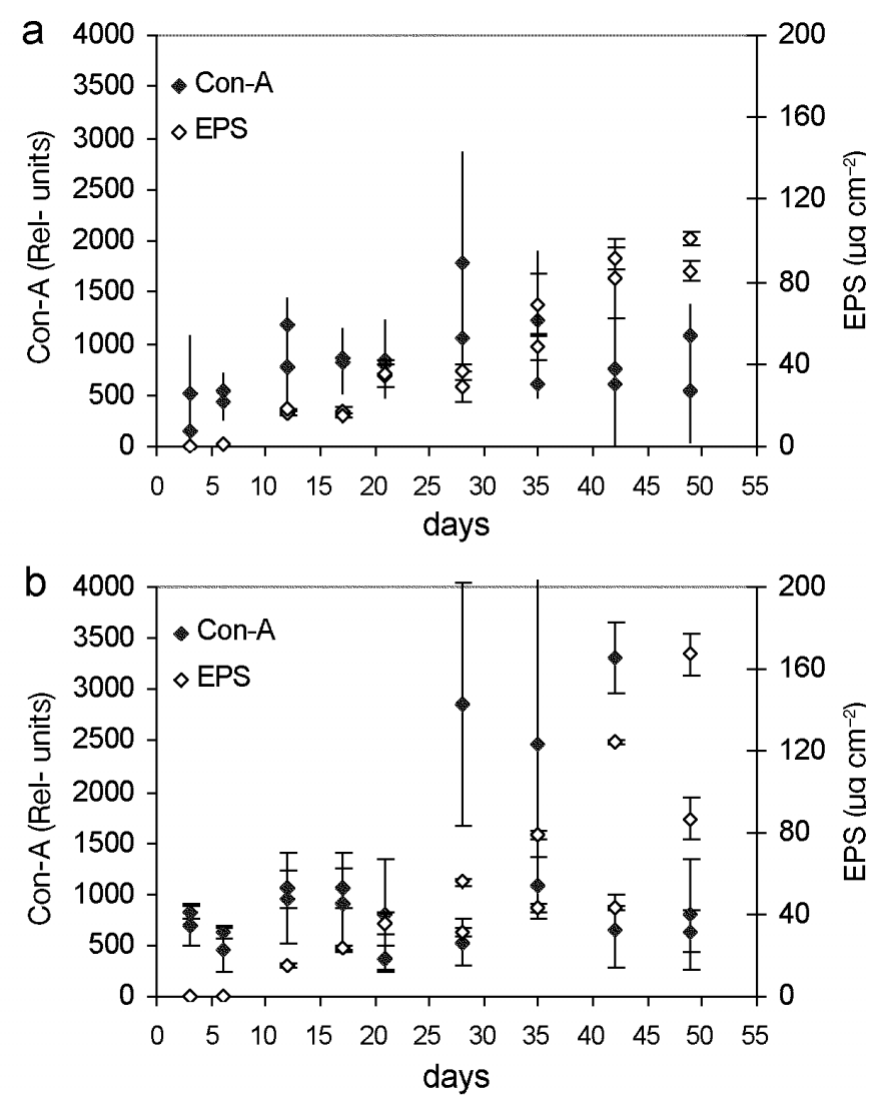

Fig. 5. EPS concentration as determined by extraction with water and acid (loose + bound EPS) and EPS concentration measured with CLSM (Con-A) for the different biofilms studied, from bare surfaces to mature biofilms. (a) Thin, compact, heavily grazed biofilms; (b) non-grazed biofilms

\section{DISCUSSION}

Our results showed that light attenuation becomes considerable in thick mature biofilms, causing a limitation of optical methods for the quantification of parameters such as biomass or photosynthetic activity across the whole biofilm depth. For currently available PAM fluorimeters, light attenuation can become a critical limiting factor (Kromkamp et al. 1998), and the algal biomass measured on dark-adapted samples will not be detected above 6 to $7 \mu \mathrm{g} \mathrm{chl} \mathrm{a} \mathrm{cm}^{-2}$, depending on the fluorimeter used.

In the case of multi-wavelength fluorescence (PHYTOPAM), it appeared that some previous information on the main species composing the biofilms is crucial. The algal composition of complex natural biofilms may prove difficult to evaluate using exclusively PAM fluorimetry, but microscopic observations may give information on which reference spectrum is appropriate (Schreiber 2002, van der Grinten et al. unpubl.).
CLSM revealed very useful information on the early stages of biofilm development, being more sensitive than HPLC and PAM fluorimetry. Early development of the biofilm, in which the proportion of algae, bacteria and EPS changes rapidly, can be plotted as the percentage of the different signals and give a relative quantification of the biofilm communities, together with the spatial distribution of the different biofilm components. This is especially important when analyzing the processes of biofilm formation on clean
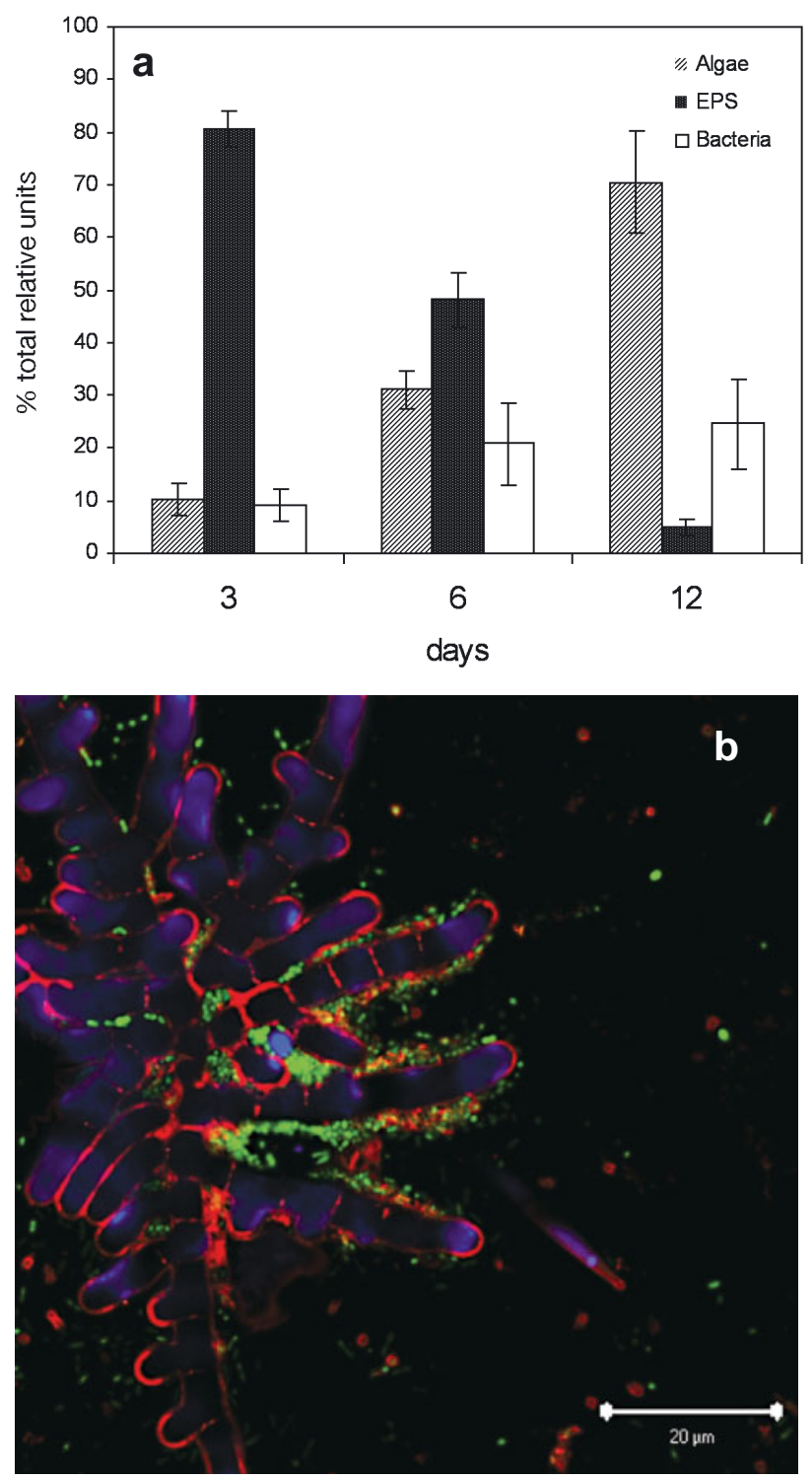

Fig. 6. (a) Relative contribution to the total CLSM signal of bacteria (Syto 9), algae (autofluorescence) and EPS (ConA) in 3,6 and $12 \mathrm{~d}$ old biofilms. (b) An optical section scan of a $12 \mathrm{~d}$ old biofilm (10-20 $\mu \mathrm{m}$ thickness) and the 3 components: algae-blue; EPS — red; bacteria - green. Objective: PlanNeofluar $100 \times / 1.3$ oil 
surfaces, as bacteria can attach after only $3 \mathrm{~h}$ and complete biofilms are reported after $24 \mathrm{~h}$ (Chae \& Schraft 2000).

Nevertheless, when using CLSM (but not PAM fluorimetry), the density of the biofilms played a role in the detection of chl a by CLSM, as the light penetration and signal attenuation depended also on the degree of compactness of the biofilm. This implies that for developing biofilms it cannot be predicted a priori when the signal will start to underestimate algal biomass. A standard correction for attenuation of the signal was not possible because of the strong influence of the chemical/physical and structural characteristics of the biofilm under investigation, as clearly indicated in Fig. 3c. More compact biofilms will have a higher attenuation of the fluorescent signal than loose biofilms, where discontinuities in the structure enhance signal intensity. The differences in biomass distribution with an increasing thickness explain why the underestimation of the algal signal measured by CLSM in well-developed biofilms is not constant.

Although CLSM failed to show the increase in EPS throughout the complete development of the biofilms, it showed EPS present as a major biofilm component in the early developmental stages, below the detection limit of the chemical extraction. In mature biofilms, when biofilm compartments were measured by means of dyes, the attenuation of light was not the only limiting factor; moreover, the attenuation was greater than that experienced when measuring autofluorescence. The penetration of dyes in compact thick biofilms may be also hindered by the biofilm matrix itself, which would explain why the signals of Con-A and Syto 9 apparently had a shorter depth range than the autofluorescence signal of the algae. In the case of the Syto 9, the stabilization of the bacterial biomass after Day 12 (when the chlorophyll was still exponentially increasing) must also have been underestimated due to the lack of penetration of the dye. Although we did not perform bacterial counts, it is known that bacterial numbers increase jointly with microalgal biomass in biofilms (Romaní \& Sabater 1999).

An additional reason for the incomplete lectin staining in older biofilms may be that the phototrophic algae in the films produce different glycoconjugates over time. Lectins have been reported to be suitable probes for in situ staining of lectin-specific glycoconjugates in the EPS of microbial films (Neu et al. 2001). It was suggested that a specific microbial community has to be tested against a panel of lectins with different specificities in order to select the most suitable lectin. In our study we used a lectin with a broad specificity (ConA) in order to stain a major fraction of the EPS glycoconjugates. Nevertheless, this may not be the best lectin for staining a major volumetric part of the
EPS glycoconjugates. Very recently, the complete range of commercially available lectins was assessed for their ability to stain in biofilms grown under different substrate conditions (Staudt et al. 2003). It is expected that there are other lectins more suitable for phototrophic biofilms.

The characteristics of the light attenuation in CLSM will also depend on the laser wavelength and intensity, filters and objectives used. In the case of the study by Neu \& Lawrence (1997), the development of biofilms thicker than $35 \mu \mathrm{m}$ could be assessed, but these biofilms formed ridges and furrows, allowing better detection of the signal. However, detection was limited to $150 \mu \mathrm{m}$, while natural biofilms can develop into mats of several mm thickness. The laser microscopy analysis of thick biofilms maybe done using 2-photon excitation. This technique using infrared light allows better detection of fluorescence signal in microbiological samples (Vroom et al. 1999). Recently, several stains including lectins have been assessed for their suitability in 2-photon excitation. Furthermore, the possibility to detect algal autofluorescence after 2-photon excitation has been shown (Neu et al. 2002). However, if biofilm samples become too thick, the only option may be embedding and physical sectioning. This has been demonstrated in bacterial films as well as in cyanobacterial films (Huang et al. 1996, Decho \& Kawaguchi 1999). Nevertheless, the possibility of observing the 3D structure for hundreds of $\mu \mathrm{m}$ on fully hydrated undisturbed biofilms by CLSM remains a clear advantage with respect to any other microscopy method.

Amann \& Kühl (1998) pointed out the value of combining different methods to study the structure and functioning of microbial communities, and this statement still holds true. Although the optical methods and dyes are being constantly diversified and improved, a combination of destructive with optical methods is still needed to assess the whole developmental period of highly dynamic biofilm communities. Optical methods will provide an accurate representation of the composition (algae, bacteria, EPS and other extracellular exudates) and activity (i.e. photosynthesis) in young biofilms, assessing the qualitative and quantitative changes of the early stages of development. Nevertheless, light attenuation and limited dye penetration will make destructive methods necessary for the quantification of the different components in thicker, mature biofilms.

Acknowledgements. This study was financed by the European project BIOFILMS, Contract number EVK1-CT-199900001. We would like to thank M. Savenije (Swammerdam Institute for Life Sciences, Faculty of Science, University of Amsterdam) for providing the image-analyzing software and W. Takkenberg for technical assistance. 


\section{LITERATURE CITED}

Amann R, Kühl M (1998) In situ methods for assessment of microorganisms and their activities. Curr Opin Microbiol 1:352-358

Barranguet C, Kromkamp J (2000) Estimating primary production rates from photosynthetic electron transport in estuarine microphytobenthos. Mar Ecol Prog Ser 204: $39-52$

Barranguet C, Herman PMJ, Sinke JJ (1997) Microphytobenthos biomass and community composition studied by pigment biomarkers: importance and fate in the carbon cycle of a tidal flat. J Sea Res 38:59-70

Battin TJ, Buttirini A, Sabater F (1999) Immobilization and metabolism of dissolved organic carbon by natural sediment biofilms in a Mediterranean and temperate stream. Aquat Microb Ecol 19:297-305

Becker K (1996) Exopolysaccharide production and attachment strength of bacteria and diatoms on substrates with different surface tensions. Microb Ecol 32:23-33

Chae MS, Schraft H (2000) Comparative evaluation of adhesion and biofilm formation of different Listeria monocytogenes strains. Int J Food Microb 62:103-111

de Beer D, Stoodley P, Roe F, Lewandowski Z (1994) Effects of biofilm structure on oxygen distribution and mass transport. Biotechnol Bioeng 43:1131-1138

Decho AW, Kawaguchi T (1999) Confocal imaging of in situ natural microbial communities and their extracellular polymeric secretions using nanoplast resin. BioTechniques 27:1246-1251

Dubois M (1959) Colorimetric method for determination of sugars and related substances. Anal Chem 28:350-356

Gawne B, Wang Y, Hoagland KD, Gretz MR (1998) Role of bacteria and bacterial exopolymer in the attachment of Achnanthes longipes (Bacillariophyceae). Biofouling 13: 137-156

Genty B, Briantais J, Baker NR (1989) The relationship between the quantum yield of photosynthetic electron transport and quenching of chlorophyll fluorescence. Biochim Biophys Acta 990:87-92

Goto N, Mitamura O, Terai H (2001) Biodegradation of photosynthetically produced extracellular organic carbon from intertidal benthic algae. J Exp Mar Biol Ecol 257: $78-86$

Herbert-Guillou D, Tribollet B, Festy D (2000) Influence of the hydrodynamics on the biofilm formation by mass transport analysis. Bioelectrochemistry 53:119-125

Huang CT, McFeters GA, Stewart PS (1996) Evaluation of physiological staining, cryoembedding and autofluorescence quenching techniques on fouling biofilms. Biofouling 9:269-277

Kromkamp J, Barranguet C, Peene J (1998) Determination of microphytobenthos Photosystem II quantum efficiency and photosynthetic activity by means of variable chlorophyll fluorescence. Mar Ecol Prog Ser 162:45-55

Lawrence JR, Neu TR, Swerhone GDW (1998) Application of multiple parameter imaging for the quantification of algal,

Editorial responsibility: Kevin Carman,

Baton Rouge, Louisiana, USA bacterial and exopolymer components of microbial biofilms. J Microbiol Methods 32:253-261

Muller M (2002) Introduction to confocal fluorescence microscopy. Shaker Publishing BV, Maastrich

Neu TR, Lawrence JR (1997) Development and structure of microbial biofilms in river water studied by confocal laser scanning microscopy. FEMS Microbiol Ecol 24:11-25

Neu TR, Lawrence JR (2002) Laser scanning microscopy in combination with fluorescence techniques for biofilm study. In: Bitton G (ed) The encyclopedia of environmental microbiology, Vol 4. John Wiley \& Sons, New York, p 1772-1788

Neu TR, Swerhone GDW, Lawrence JR (2001) Assessment of lectin-binding analysis for in situ detection of glycoconjugates in biofilm systems. Microbiology 147:299-313

Nielsen P, Jahn HA (1999) Extraction of EPS. In: Wingender J, Neu TR, Flemming HC (eds) Microbial extracellular polymeric substances. Characterization, structure and function. Springer-Verlag, Heidelberg, p 49-72

Okkerse WJH, Ottengraf SPP, Osinga-Kuipers B (2000) Biofilm thickness variability investigated with a laser triangulation sensor. Biotechnol Bioeng 70:619-629

Percival SL, Walker JT, Hunter PR (2000) Microbiological aspects of biofilms and drinking water. CRC Press, Boca Raton, FL

Rince Y, Lebeau T, Robert JM (1999) Artificial cell-immobilization: a model simulating immobilization in natural environments? J Appl Phycol 11:263-272

Romaní AM, Sabater S (1999) Effect of primary producers on the heterotrophic metabolism of a stream biofilm. Freshw Biol 41:729-736

Schreiber U, Gademann R, Bird P, Ralph PJ, Larkum AWD, Kühl M (2002) Apparent light requirement for activation of photosynthesis upon rehydration of desiccated beach rock microbial mats. J Phycol 38:125-134

Smith DJ, Underwood GJC (2000) The production of extracellular carbohydrates by estuarine benthic diatoms: the effects of growth phase and light and dark treatment. J Phycol 36:321-333

Staats N (1999) Exopolysaccharide production by marine benthic diatoms. $\mathrm{PhD}$ thesis, University of Amsterdam

Staudt C, Horn H, Hempel DC, Neu TR (2003) Screening of lectins for staining lectin-specific glycoconjugates in the EPS of biofilms. In: Lens $\mathrm{P}$, Moran AP, Mahony $\mathrm{T}$, Stoodley P, O'Flaherty V (eds) Biofilms in medicine, industry and environmental biotechnology. IWA Publishing, London, p 308-327

Steinman AD (1996) Effects of grazers on freshwater benthic algae. In: Stevenson RJ, Bothwell ML, Lowe RL (eds) Algal ecology. Academic Press, San Diego, p 341-373

Vroom JM, Grauw DCJ, Gerritsen HC, Bradshaw AM, Marsh PD, Watson GK, Birmingham JJ, Allison C (1999) Depth penetration and detection of $\mathrm{pH}$ gradients in biofilms by two-photon excitation microscopy. Appl Environ Microbiol 65:3502-3511

Wimpenny J, Manz W, Szewzyk U (2000) Heterogeneity in biofilms. FEMS Microbiol Rev 24:661-671

Submitted: May 8, 2003; Accepted: September 15, 2003

Proofs received from author(s): November 26, 2003 